\title{
Correction to: Research on the Influences of Time Harmonics on Permanent Magnet Synchronous Motors with Hybrid Magnet Poles
}

\author{
Hongbo Qiu ${ }^{1}$ Yuedong Guo ${ }^{1}$. Wenfei Yu ${ }^{1} \cdot$ Bingxia Tang ${ }^{2} \cdot$ Cunxiang Yang ${ }^{1}$
}

Published online: 26 April 2019

(c) The Korean Institute of Electrical Engineers 2019

\section{Correction to: \\ Journal of Electrical Engineering \& Technology https://doi.org/10.1007/s42835-019-00166-1}

Due to an unfortunate oversight the acknowledgment has been omitted:

This work was supported in part by the National Natural Science Foundation of China under Grant 51507156, in part by the University Key Scientific Research Programs of Henan province under Grant 17A470005, and in the part by the Graduate's Scientific Research Foundation of Zhengzhou University of Light Industry under Grant 2017010.
Publisher's Note Springer Nature remains neutral with regard to jurisdictional claims in published maps and institutional affiliations.

The original article can be found online at https://doi.org/10.1007/ s42835-019-00166-1.

\author{
Wenfei Yu \\ bijiaohao22@163.com \\ Hongbo Qiu \\ qiuhongbohrb@163.com \\ Yuedong Guo \\ guoyuedong111@163.com \\ Bingxia Tang \\ tbx1717@163.com \\ Cunxiang Yang \\ yangcx77777@163.com
}

1 Department of Electrical and Information Engineering, Zhengzhou University of Light Industry, Zhengzhou, China

2 Zhengzhou Water Supply, Investment Holdings Co. Ltd, Zhengzhou, China 